\title{
MODELLING THE DETERMINANTS OF ADOPTION OF MULTIPLE CLIMATE CHANGE COPING AND ADAPTATION STRATEGIES: A MICRO ANALYSIS OF SMALLHOLDER FARMERS IN NORTHERN GHANA
}

\author{
Shaibu Baanni AZUMAH *1 (D), Abass MAHAMA ${ }^{2}$ (iD), Samuel A. DONKOH ${ }^{2}$ (iD
}

\begin{abstract}
Address:
${ }^{1}$ Solidaridad Network, West Africa. Hse No. 18, Okine Street, East Legon, Accra PMB KD 11, Kanda, Accra, Ghana. ${ }_{2}^{2}$ Department of Agriculture and Resource Economics. University for Development Studies, P. O. Box TL 1350. Tamale, Ghana.

*Corresponding author: raszumah1983@gmail.com
\end{abstract}

\begin{abstract}
Climate change coping and adaptation (CCCA) mechanisms have become more relevant in the north of Ghana where there is evidence of severe impacts of climate change and poverty. In this study, we modelled the determinants of adoption of multiple CCCA strategies by smallholder farmers in northern Ghana using primary data collected from 230 households. Count data models including endogenous switch Poisson and generalized Poisson regression were estimated to account for potential endogeneity of credit, as well as dispersion errors. The credit variable did not show signs of endogeneity, neither was there evidence of significance dispersion errors in the data. Age, sex, extension visits, and farm size were significant across the various count data models and should be considered by policy makers when designing national climate change response and mitigation plans.
\end{abstract}

Keywords: Climate change, Adaptation, Count data, Poisson regression, Smallholder farmers

JEL: R52, R58, H41

\section{INTRODUCTION}

Although there have been several interventions aimed at improving the livelihoods of people, poverty is still widespread in many countries including Ghana (GSS, 2013). Poverty reduction has therefore, become the core challenge for development in recent times. A lot has been achieved since the millennium declaration to halve extreme poverty by 2015 , with a shift now towards Sustainable Development Goals (SDGs). However, climate change poses a serious challenge to poverty reduction, and could undo the successes of developmental efforts in the last few decades that are aimed at achieving a resilience for rural households.

The IPPC (2001) defined climate change as a "change in the statistical properties of the climate system when considered over long period of time, regardless of cause". In poverty endemic countries, climate change manifest in many forms especially as naturally occurring disasters that cause great destruction to livelihoods. Climate change also manifest in floods and droughts and can increase the incidence of pest and waterborne-related diseases, as well as cause lower crop yields among resource poor farmers (Hallegatte et al., 2016). Hallegatte et al. (2016) further asserts that vulnerability to poverty will persist should climate change continue.

Addressing poverty situations without recourse to the impacts of climate change on livelihoods of poor households in developing countries will lead to failed poverty management and reduction processes. This concern stems from the overly dependence of many developing countries on natural resources (for example, agriculture and fishing) that are prone to the effects of climate change for their livelihoods and sustenance, and the fact that many of these developing countries do not have enough technical and financial capacities to adequately deal with increasing risk of climate change (Skoufias et al., 2011).

According to FAO (2016), small-scaled farmers in Ghana's poor rural areas have poor access to the productive assets that could facilitate agricultural modernization and commercialization. Some constraints to rural livelihoods include the lack of infrastructure and mechanization equipment such as storage facilities, harvesting and processing machines, as well as dysfunctional market system. There is also limited financial and technical support services such as agricultural extension and research.

The northern regions of Ghana have experienced variable and unpredictable climate in the past few decades. Floods and droughts occur in the area just within some few months apart, posing serious threat to food security for smallholder led households. Some coping and adaptation measures are therefore needed to mitigate against the effects of climate change. Contextually, CCCA strategies are said to be actions that people take in response to, or in anticipation of changing climate conditions. These actions purport to reduce the adverse impacts of climate change on exposed households (Tompkins and Adger, 2003). While adaptation measures are long term in nature, coping strategies are short term measures (Azumah et al., 2017). The UNFCCC (2007b) projected that, agricultural 
productivity and for that matter, access to food would be seriously affected due to the changing climate in many African countries. Similarly, a report by the FAO (2016) affirms that climate change is influencing and will continue to pose a serious threat to crop yields; and will account for a $5 \%$ and $30 \%$ reduction in overall yields by 2030 and 2080 respectively. This challenge will further compound when variability in climatic conditions increases. For instance, changes in rainfall pattern and temperature levels can lead to crop and asset losses, further exacerbating the poverty levels especially for rural and marginalized groups due to their inability to adapt and cope with adverse climatic conditions.

In the last few decades, the climate in Ghana has changed drastically. Excessive heat and torrential rains have caused massive destruction of most arable lands and crops. The northern regions of Ghana have started experiencing this phenomenon and have been identified as highly vulnerable to the impacts of climate change (Antwi-Agyei et al., 2012). A forecast report by the World Bank indicates that, for the periods 2010 - 2050 Ghana would experience warming with high temperatures recorded in northern Ghana (Asante and AmuakwaMensah, 2015). Similarly, a recent study (Fagariba et al., 2018) indicates that extreme temperature and drought occurrences are eminent in northern Ghana. This has a profound effect on food security, poverty and malnutrition (Azumah et al., 2017). Extant studies have identified and assessed CCCA mechanisms used by rural smallholder households in northern Ghana to mitigate the effects of prolong droughts on their livelihoods (e.g. Bawakyillenuo et al., 2016; Antwi-Agyei et al., 2014; Codjoe et al., 2012). For instance, the authors found that most smallholders in northern Ghana used coping and adaptation strategies such as migration (temporary), planting drought tolerant crop varieties, agriculture intensification, and extensification, application of chemical fertilizer, diversifying agriculture among many others. Earlier studies including Teye et al. (2015) and Codjoe et al. (2014) have paid attention to some indigenous strategies employed by farmers in mitigating the effects of the changing climate by smallholder farmers towards building resilient livelihoods. Recent studies including Lawson et al. (2019), Antwi-Agyeia et al. (2018), Assan et al. (2018) and Fagariba et al. (2018) also explored CCCA opportunities and strategies used by farmers in northern Ghana. Whilst these studies have documented sufficient literature on appropriate adaptation strategies, specific studies that focus on factors that influence farmers' intensity of adoption of CCCA strategies in northern Ghana is very limited.

Many studies relating to intensity of adoption have found interesting results using the Poisson regression model, however, the findings may not be entirely reliable because of failure to account for potential incidence of endogeneity. This study therefore presents an econometric model that in our opinion, best investigates factors that influence adoption intensity of CCCA strategies in northern Ghana while considering critically, the nature of dispersion and potential incidence of endogeneity that may affect the efficiency and consistency of the estimates.

\section{DATA AND METHODS}

\section{Study location}

The study was conducted in the north of Ghana. The northern Savannah regions lie between latitudes $8^{\circ} \mathrm{N}$ and $11^{\circ} \mathrm{N}$ and covers almost two third of Ghana's land mass (Amikuz uno and Donkoh, 2012). The rainfall pattern of the region is erratic and characterized by a long dry period of about seven months from October to May each year. Annual precipitation in the north of Ghana ranges between $400 \mathrm{~mm}$ and $1200 \mathrm{~mm}$. Agriculture in the area is largely under rainfed conditions, and employs close to $70 \%$ of the employable population (GSS, 2013). Land degradation is eminent in the area, resulting declining soil fertility which has impact on the farming systems. The choice of the region for this study is based on the sensitivity of the area to climate variability and climate change (Amikuzuno and Donkoh, 2012), especially erratic rainfall and high temperature (Kranjac Brisavljevic et al., 1999). The region is also blessed with agricultural activities but with high percentage of subsistent poor farmers (GSS, 2013).

\section{Sampling and data collection}

A multi-stage sampling procedure was employed to select the target farmers. The first stage involved the use of purposive sampling technique to select six districts that are adversely affected by the impacts of climate change. A simple random sampling method was then used in the second stage to randomly pick two communities from each of the six districts, totally 12 communities. Again, simple random sampling technique was employed to select 20 respondents from each of the 12 communities, resulting to a sample size of two hundred and forty (240). However, a total of 230 of the questionnaires that were returned contained all the necessary information for analyses. Primary research data was collected from farm households using semi-structured questionnaire which allowed for some flexibility in the responses provided by respondents, such that their views could be captured totally. Additionally, secondary data was sourced from a few Government and Non-governmental Organisations such as MoFA, ACDEP, and the Presbyterian Agricultural Services, using interview guides.

\section{Analytical framework}

Increasingly, count data models are becoming valuable econometric models for analysis of data with count events (Miranda, 2004). Several count data models have been used in many studies to explain intensity of adoption of various technologies. Many of these count data models can produce reliable estimates only when the regressors exhibit exogeneity. The reverse can be said when the regressors are endogenous in nature. Dealing with endogeneity and selection bias requires the choice of an appropriate and efficient estimator. Many studies have explored a good number of estimators that address potential endogeneity and sample selection bias in count data analysis (Wooldridge, 2010; Terza et al., 2008; Mullahy, 1997; Van Ophem, 2000; Schellhorn, 2001; Miranda, 2004; Li and Trivedi, 2009). These estimators are different in their structural formulation and parameterization. 
In this study, several count data models where applied to deal with different estimation errors that may come about. The endogenous switch Poisson (ESP) is applied to deal with potential endogeneity associated with access to credit. The analysis of the effect of credit access on intensity of adoption of CCCA strategies provides a perfect case scenario of the problem of endogeneity. The endogenous switch count data model follows a two-stage estimation procedure. First, an exogenous switching is performed to show the extent of dispersion, a significant sigma shows that the data is over dispersed and insignificant sigma gives an indication of either under dispersed or equi-dispersed data, which may call for a generalized Poisson model to correct. In the second stage of estimation, endogenous switching is performed to confirm the presence of endogeneity. A significant rho indicates the presence of endogeneity and therefore confirms the appropriateness of the endogenous switch Poisson regression model.

\section{The Endogenous Switching Poisson (ESP) model}

Given the $i^{\text {th }}$ farmer from a random sample $I=\{1 \ldots \ldots n)$ conditional on a vector of explanatory variables $x_{i}$, an endogenous dummy $c_{i}$, and a random term $\varepsilon_{i}$, the dependent variable $y_{i}$, which is a count, is supposed to follow a standard Poisson distribution (Miranda, 2004; Terza, 1998 (Eq.1).

$$
f\left(y_{i} / \varepsilon_{i}\right)=\frac{\exp \left\{-\exp \left(x_{i}^{\prime} \beta+\gamma c_{i}+\varepsilon_{i}\right)\right\}\left\{\exp \left(x_{i}^{\prime} \beta+\gamma c_{i}+\varepsilon_{i}\right)\right\}^{y_{i}}}{y_{i} !}
$$

Where: $\beta$ and $\gamma$ are coefficient to be estimated. The error term $\varepsilon_{i}$ measures omitted and unobserved variables as well as any measurement error. Given a vector of explanatory variables $z_{i}$ (which may contain some or all elements) and $x_{i}, c_{i}$ is characterised by an index process (Eq. 2).

$c_{i}=\left\{\begin{array}{l}1 \text { if } z_{i} \alpha+v_{i}>0 \\ \text { 0otherwise }\end{array}\right.$

Where: $\alpha$ is a vector of coefficients to be estimated. Suppose that $w_{i}$ denotes all endogenous variables and $\varepsilon_{i}$ and $v_{i}$ are jointly normal with mean zero and covariance matrix $\sum=\left(\begin{array}{l}\sigma^{2} \sigma p \\ \sigma p 1\end{array}\right)$, given that $\varepsilon_{i}, c_{i}$ and $y_{i}$ are independent. Hence, the joint conditional probability density function of $y_{i}$ and $c_{i}$, given $w_{i}$, can be written as Eq. 3.

$$
\begin{aligned}
& f\left(y_{i}, c_{i} / w_{i}\right)=\int_{-\infty}^{\infty}\left\{c _ { i } f ( y _ { i } / c _ { i } = 1 , w _ { i } , \varepsilon _ { i } ) \operatorname { P r } \left(c_{i}=\right.\right. \\
& \left.1 / w_{i}, \varepsilon_{i}\right)+\left(1-c_{i}\right) f\left(\left(y_{1} / c_{1}=0, w_{i}, \varepsilon_{i}\right)\right) \operatorname{Pr}\left(c_{i}=\right. \\
& \left.\left.0 / w_{i}, \varepsilon_{i}\right)\right\} f\left(\varepsilon_{i}\right) c_{i} \varepsilon_{i}
\end{aligned}
$$

Where: $f\left(\varepsilon_{i}\right)$ represents the probability density function for the random error term, $\varepsilon_{i}$.

\section{The Generalized Poisson Model}

The Generalized Poisson Regression (GPR) model has been suggested as it is a flexible count data approach in handling count data of any nature to cover dispersion errors (Famoye et al., 2004). If the generalized Poisson distribution function is normalized, given a random variable $Y$ then its probability mass distribution function can be mathematically written as Eq. 4 .

$f\left(y_{i}, \pi_{i}, \delta\right)=\frac{\pi_{i}\left(\pi_{i}+\delta y_{i}\right)^{\lambda_{i}^{-1} \lambda^{-\pi_{i}-\delta y_{i}}}}{y_{i} !}, y_{i}=1,2 \ldots \ldots n$

Where $\pi_{i}>0$ and $\max \left(-1, \pi_{i}\right)<\delta, 1 . \quad y_{i}$ denotes the various practices adopted by farmers. The variance and mean of the random variable $y_{i}$ can be computed as Eq. 5 .

$u_{i}=E\left(y_{i}\right)=\frac{\pi_{i}}{1-\delta}, \operatorname{var}\left(y_{i}\right)=\frac{\pi_{i}}{(1-\delta)^{3}}=\frac{1}{(1-\delta)^{2}} E\left(y_{i}\right)=$

$\alpha E\left(y_{i}\right)$

The $\alpha=\frac{1}{(1-\delta)^{2}}$ represents the dispersion factor in the GPR model. So, if we have $\delta=0$ then there is evidence of equi-dispersion and standardized PR model is preferred. Conversely, if it is found that $\delta>0$ then overdispersion is presence. Again, if $\delta<0$ it indicates underdispersion which supports the use of GPR model as in this study. The log likelihood estimation of the GPR model is given by the Eq. 6 .

$L=\sum_{i=1}^{n} L\left(\pi_{i}, \delta ; y_{i}\right)=\sum_{i=1}^{n} \operatorname{In} L\left(\pi_{i}, \delta ; y_{i}\right)=$ $\sum_{i=1}^{n}\left\{\operatorname{In}_{i}+\left(y_{i}-1\right) \operatorname{In}\left(\pi_{i}+\delta y_{i}\right)-\left(\pi_{i}+\delta y_{i}\right)-\right.$ Iny $y_{i}$ !

\section{RESULTS AND DISCUSSION}

\section{Measurement of variables}

Table 1 shows the description and statistics of variables used in the study. The average age was found to be 39.7 years. About 73.4 percent of the respondents were male. The average extension visits received by farmers was 2.51 times per season, implying farmers had some significant visits which could result in adoption of CCCA strategies. The results from Table 1 show that about 69 percent of farmers had access to credit either in the form of cash or farm inputs. This has an implication of impacting on the number of CCCA strategies adopted. The average farm size cultivated by farmers was estimated as 0.80 hectares, implying farmers cultivate relatively small sizes of farmland. Also, the average household size in the study area was found to be 13.59, suggesting a high household size which potentially could affect adoption of multiple CCCA strategies. The results also show that the average number of CCCA strategies adopted by farmers was 5.33.

\section{Factors influencing intensity of adoption of CCCA strategies}

Before discussing the factors that influence farmers' multiple subscription to various CCCA mechanisms, we first present the distribution of the identified coping and adaptation mechanisms (Table 2), as well as the adoption intensity (Table 3). In all, fourteen CCCA were identified and included for analysis. The results from Table 2 reveal that 2.71 percent of farmers adopted income diversification strategies to cope with the effects of climate change. 
Table 1. Summary statistics of variables $(n=230)$

\begin{tabular}{lcrr}
\hline Definition of Variable & A priori Expectation & Mean & Std. Dev. \\
\hline Age (years) & + & 39.7 & 10.95 \\
Sex & $+/-$ & 0.734 & 0.442 \\
Extension (number of contacts) & + & 2.51 & 1.86 \\
Credit (farmers' access to credit) & + & 0.69 & 0.46 \\
Farm size (in hectares) & + & 0.8 & 0.41 \\
Household size & + & 13.59 & 7.93 \\
Intensity of adoption of Climate change & n/a & 5.33 & 2.62 \\
coping strategies (0-12) & & & \\
\hline
\end{tabular}

Source: Analysis of field data, 2019

Table 2: Adoption of CCCA strategies by farmers $(n=230)$

\begin{tabular}{lcr}
\hline Strategy & Freq. & Percent \\
& No. of farmers who adopted \\
\hline Mulching & 30 & 13.04 \\
Spraying & 204 & 88.7 \\
Mixed cropping & 151 & 65.65 \\
Mixed farming & 162 & 70.43 \\
Crop rotation & 116 & 50.43 \\
Improved seed & 97 & 42.17 \\
Dug out & 9 & 3.91 \\
Irrigation & 3 & 1.30 \\
Changing planting time & 53 & 23.04 \\
Diversification & 5 & 2.71 \\
Raised beds & 111 & 48.26 \\
Manual ploughing & 103 & 44.78 \\
Row sowing & 172 & 74.78 \\
Bunding & 12 & 5.22 \\
\hline Source: Anlysis of field & &
\end{tabular}

Source: Analysis of field data, 2019

Table 3: Adoption intensity of CCCA strategies

\begin{tabular}{lrr}
\hline Intensity of adoption & Freq. & Percent \\
\hline 0 & 7 & 3.0 \\
1 & 20 & 8.7 \\
2 & 11 & 4.8 \\
3 & 24 & 10.4 \\
4 & 26 & 11.3 \\
5 & 24 & 10.4 \\
6 & 23 & 10.0 \\
7 & 23 & 10.0 \\
8 & 63 & 27.4 \\
9 & 6 & 2.6 \\
10 & 1 & 0.4 \\
11 & 1 & 0.4 \\
12 & 1 & 0.4 \\
\hline Mean adoption & & 5.33 \\
Variance & & 6.86 \\
N & & 230 \\
\hline Source: Analysis of field data & 2019 &
\end{tabular}

Source: Analysis of field data, 2019

Also, just 1.3 percent of farmers used irrigation to cope with climate change. The results also show that about 88.70 percent of farmers adopted spraying to kill weeds and insects to cope with the effects of climate change. Also, 65.65 percent, 70.43 percent, 50.43 percent and 42.17 percent adopted mixed cropping, mixed farming, crop rotation, and improved seed respectively. Also, a good number of farmers $(74.78 \%$ ) adopted row planting to increase crop density in order to cope with climate change effects.
The dependent variable was modelled as intensity of adoption of CCCA strategies premised on the number of strategies adopted. The results from Table 3 reveal that 3.04 percent of farmers did not adopt any of the CCCA strategies. Also, 8.70 percent of farmers adopted only 1 strategy. The results also reveal that 4.78 percent of farmers adopted only 2 of the strategies, whereas 10.43 percent, 11.30 percent and 10.43 percent adopted 3, 4 and 5 CCCA strategies respectively. Similarly, 27.39 percent of the farmers adopted 8 of the CCCA strategies while only 0.43 percent adopted 12 of the climate change coping strategies. No farmer adopted 13 or all 14 identified mechanisms at the same time.

Several diagnostic tests were also performed to choose the appropriate model. The results from Table 3 show that the conditional mean of the outcome variable is 5.33 and its associated variance is 6.86 , indicating that the data may be over-dispersed. The over-dispersed nature of the data was unjustified in the sense that the probability of sigma in the exogenous switch (EXS) and endogenous switch (ES) models was insignificant (Table 4). The result therefore suggests that the Poisson model may be an appropriate measure for the data. However, in order to validate the correctness of our estimates in the Poisson model, we estimated the endogenous switch (ENS) which corrects for both endogeneity and sample selection bias, by assuming the credit variable to be endogenous. The rho as presented in Table 5 was found to be insignificant, implying that that there was no reported incidence of endogeneity, therefore, still supporting the use of a standard Poisson model in estimating the data. 
Also, a comparison of the AIC and BIC values of the four models appears to be consistent with the decision to settle on the Poisson model. The estimated results in the EXS and ENS did not produce any significant difference in the loglikelihood value or did not result in any improvement in the estimates. Furtherance to this shows that the estimates of the Poisson are not significantly different from that of the EXS and ENS since the estimates were virtually the same.

Following the arguments (Erdman et al., 2008; Greene, 2002; Cameron and Trivedi, 1999) of an almost impossible occurrence of equi-dispersion in real life data, we further estimated the Generalized Poisson Regression (GPR) model (Table 5) to check for potential underdispersion of the data. Further diagnostics of the models suggest otherwise, the dispersion parameter (-0.067) reveals that the data was seemingly under-dispersed, with the standard errors of the normal Poisson model quite larger than those of the generalized Poisson model. Also, the loglikelihood value of the generalized Poisson model was found to be larger than that of the standard Poisson model, thereby, supporting the appropriateness of the generalized Poisson model over the standard Poisson model. Following the work of Nkegbe and Shankar (2014), the presence of under-dispersion means that both equi-dispersion and over-dispersion will produce inefficient estimates. Therefore, our discussion of the estimates (Table 5) is based on the generalized Poisson regression model.

All estimated variables except for credit and household size were significant at $1 \%$ in explaining adoption intensity (Table 5). The direction of the signs of the coefficients were also consistent with the a priori expectations in all three models. Age had a significant and positive effect on intensity of adoption of CCCA strategies, implying that older farmers have higher probability of adopting many strategies than younger farmers.

As expected, there was a positive relationship between extension visits and intensity of adoption of CCCA strategies, implying that the more farmers received visits by extension agents the more likely they are to adopt mul tiple climate change coping/adaptation strate gies. This result is supported by finding of Azumah et al. (2017), and Obeng $\boldsymbol{e t}$ al. (2016) who also found a positive and significant association between extension services and adoption of CCCA strategies in the northern region of Ghana. Other findings that show a positive association between access to extension and adoption of CCCA strategies in northern Ghana include Fagariba et al. (2017).

Similarly, farm size had a positive influence on intensity of adoption of CCCA strategies. This finding did not come as a surprise because increase in farm size comes with a lot of commitment in terms of investment in new strategies to either sustain or increase yields. Azumah $\boldsymbol{e t}$ al. (2017) also found a positive association between farm size and adoption of CCCA strategies in northern region of Ghana. The positive association of farm size with the of multiple CCCA strategies is corroborated by Fadina and Barjolle (2018). Even though Fagariba et al. (2018) reported an insignificant effect of farm size on adoption of CCCA strategies in the Sissala West district of the Upper West Region, the coefficient of farm size was positive indicating a relationship of a potential of increase in adoption of climate change adaptation strategies by farmers with larger farm sizes. This means that if farmers with larger farms are to combat the adverse effects of climate change effectively, adoption of a combination of coping strategies is key.

Table 4. Results of Exogenous and Endogenous Switching Poisson Models

\begin{tabular}{|c|c|c|c|c|}
\hline \multirow{2}{*}{$\begin{array}{l}\text { Model } \\
\text { Variable }\end{array}$} & \multicolumn{2}{|c|}{ Exogenous-switch Poisson } & \multicolumn{2}{|c|}{ Endogenous switch Poisson } \\
\hline & \multicolumn{2}{|c|}{ Coeff. $\quad$ Std } & Coeff. & Std \\
\hline Credit & 0.014 & 0.064 & 0.011 & 0.126 \\
\hline Age & $0.010 * * *$ & 0.002 & $0.010 * * *$ & 0.002 \\
\hline Sex & $-0.242 * * *$ & 0.072 & $-0.242 * * *$ & 0.072 \\
\hline Household size & -0.004 & 0.003 & -0.004 & 0.003 \\
\hline Extension visits & $0.071 * * *$ & 0.018 & $0.071 * * *$ & 0.018 \\
\hline Farm size & $0.518 * * *$ & 0.09 & $0.518 * * *$ & 0.09 \\
\hline Constant & 0.819 & 0.135 & 0.819 & 0.135 \\
\hline \multicolumn{5}{|l|}{ Switch } \\
\hline Age & $-0.015^{*}$ & 0.008 & $-0.015 *$ & 0.008 \\
\hline Sex & -0.162 & 0.211 & -0.162 & 0.211 \\
\hline Farm size & 0.089 & 0.233 & 0.089 & 0.233 \\
\hline Constant & 1.176 & 0.355 & 1.176 & 0.355 \\
\hline Sigma & 0 & 0.024 & 0.002 & 0.076 \\
\hline rho & - & - & 0.831 & 2.821 \\
\hline $\mathrm{LR} \mathrm{Chi}^{2}(13)$ & & 127.98 & & 127.71 \\
\hline Prob $>\mathrm{Chi}^{2}$ & & 0 & & 0 \\
\hline Pseudo $\mathrm{R}^{2}$ & & - & & - \\
\hline Log likelihood & & -636.551 & & -636.551 \\
\hline AIC & & 1297.103 & & 1299.102 \\
\hline BIC & & 1338.36 & & 1343.797 \\
\hline
\end{tabular}

Note: $* \mathrm{p}<0.1 ; * * \mathrm{p}<0.05 ; * * * \mathrm{p}<0.01$

Source: Analysis of field data, 2019 
Table 5. Parameter estimates of determinants of adoption intensity of CCCA strategies

\begin{tabular}{|c|c|c|c|c|}
\hline \multirow{2}{*}{$\begin{array}{l}\text { Model } \\
\text { Variable }\end{array}$} & \multicolumn{2}{|c|}{ Standard Poisson } & \multicolumn{2}{|c|}{ Generalized Poisson } \\
\hline & Coeff. & Std & Coeff. & Std \\
\hline Credit & 0.014 & 0.064 & 0.011 & 0.059 \\
\hline Age & $0.010 * * *$ & 0.002 & $0.010 * * *$ & 0.002 \\
\hline Sex & $-0.242 * * *$ & 0.072 & $-0.241 * * *$ & 0.067 \\
\hline Household size & -0.004 & 0.003 & -0.004 & 0.003 \\
\hline Extension visits & $0.071 * * *$ & 0.018 & $0.069 * * *$ & 0.017 \\
\hline Farm size & $0.518 * * *$ & 0.09 & $0.519 * * *$ & 0.085 \\
\hline Constant & 0.819 & 0.135 & 0.847 & 0.128 \\
\hline LR Chi $^{2}$ (13) & & 133.62 & & 125.66 \\
\hline Prob $>\mathrm{Chi}^{2}$ & & 0.000 & & 0.000 \\
\hline Pseudo $\mathrm{R}^{2}$ & & 0.118 & & 0.112 \\
\hline Log likelihood & & -497.26 & & -496.366 \\
\hline $\mathrm{AIC}$ & & 1008.532 & & 1008.733 \\
\hline $\mathrm{BIC}$ & & 1032.598 & & 1036.237 \\
\hline Dispersion & & - & & -0.067 \\
\hline \multicolumn{5}{|c|}{ Likelihood-ratio test of delta $=0$ : $\operatorname{chi} 2(1)=1.8$ Prob $>=\operatorname{chi} 2=0.0899$} \\
\hline Note: $* \mathrm{p}<0.1 ; * *$ & $0.05 ; * * * p<0.0$ & & & \\
\hline
\end{tabular}

Sex of the respondent had a negative and significant effect on the adoption intensity of CCCA strategies, corroborating with Fadina and Barjolle (2018), and Obeng et al. (2016). This finding means that female farmers are more likely to adopt more CCCA strategies and adaptation compared to their male counterparts. Similarly, a qualitative study conducted by Antwi-Agyei et al. (2018) in northern Ghana found that more female headed households were more likely to adopt climate change adaptation strategies than those headed by males. A plausible explanation to these findings including that of this study is the fact that adverse climate change has a detrimental effect on food security, income and livelihoods which translates to increasing poverty levels. Many studies have linked poverty to women as the worst affected. This implies therefore that any strategies aimed at reducing the effect of climate change on livelihoods will have more females adopting than males.

\section{CONCLUSIONS}

The impact of climate change is being felt across Africa with significant negative effects recorded among resource poor stallholder farmers in the north of Ghana. Adaptation mechanisms are therefore necessary to reduce vulnerability. This study presents an econometric model that in our opinion, best investigates the factors that influence adoption intensity of CCCA strategies among smallholder farmers in northern Ghana, while considering critically, the nature of dispersion and potential incidence of endogeneity that may affect the efficiency and consistency of the estimates. However, one important limitation is worth noting. Count data models do not account for how different factors affect adoption of specific CCCA strategies. With this adopted approach all strategies are treated equally, independent of whether a particular CCCA strategy is more or less important to cope with climate change (CC) than other ones. From the empirical results, the study concludes that without correcting for errors, the estimates of coefficients of the standard Poisson model appear inefficient. Credit did not exhibit endogeneity as the test statistic (rho) was insignificant. Age, extension visits, and farm size positively and significantly influenced the adoption of multiple CCCA strategies and should be given credence by policy makers when designing national climate mitigation and adaptation documents. Female farmers in northern Ghana must be targeted too, as they have been found to adopt many coping and adaptation mechanisms to improve resilience at household level.

\section{REFERENCES}

ANTWI-AGYEI, P., STRINGER, L.C., \& DOUGILL, A.J. (2014). Livelihood adaptation to climate variability: insights from farming households in Ghana. Reg. Environ. Change, 14: 1615-1626. DOI: https://doi.org/10.1007/s10113-014-0597-9

ASANTE, F. A., \& AMUAKWA-MENSAH, F. (2015). Climate Change and Variability in Ghana: Stocktaking. Climate, 3:78-99. DOI: http://dx.doi.org/10.3390/cli3010078

AZUMAH, S.B., DONKOH, S.A. \& ANSAH, I.G.K. (2017). Contract farming and the adoption of climate change coping and adaptation strategies in the northern region of Ghana. Environment, Development and Sustainability. Springer. 1-21. DOI: http://dx.doi.org/10.1007/s10668-016-9854-Z

BAWAKYILLENUO, S., YARO, J.A., \& TEYE, J. (2016). Exploring the autonomous adaptation strategies to climate change and climate variability in selected villages in the rural northern savannah zone of Ghana. Local Environ. 21, 361-382. DOI: http://197.255.68.203/handle/123456789/6099

CAMERON, A. C., \& TRIVEDI, P. K. (1999). Essentials of Count Data Regression (Chapter 15). In B. B.H. (Ed.), A Companion to Theoretical Econometrics. Malden, MA: Blackwell Publishing Ltd. http://cameron.econ.ucdavis.edu/research/CTE01preprint .pdf

CODJOE, S.N.A., ATIDOH, L.K., \& BURKETT, V. (2012). Gender and occupational perspectives on 
adaptation to climate extremes in the Afram Plains of Ghana. Climate Change, 431-454. DOI: https://doi.org/10.1007/s10584-011-0237-z

CODJOE, S.N.A., OWUSU, G., \& BURKETT, V. (2014). Perception, experience, and indigenous knowledge of climate change and variability: the case of Accra, a SubSaharan African city. Reg. Environ. Change, 14: 369-383. DOI: https://doi.org/10.1007/s10113-013-0500-0

ELSIE ASSAN, E., SUVEDI, M., OLABISI, L.S \& ALLEN, A. (2018). Coping with and Adapting to Climate Change: A Gender Perspective from Smallholder Farming in Ghana. Environment. 5 (86). DOI: http://dx.doi.org/10.3390/environments5080086

ERDMAN. D, JACKSON, L., \& SINKO, A. (2008). Zero-Inflated Poisson and Zero-Inflated Negative Binomial Models Using the COUNTREG Procedure. SAS Institute Inc., Cary, NC. Paper 322. https://support.sas.com/resources/papers/proceedings/pdf s/sgf2008/322-2008.pdf

FADINA, A.M.R., \& BARJOLLE, D. (2018). Farmers' Adaptation Strategies to Climate Change and Their Implications in the Zou Department of South Benin. Environment.

DOI:

https://doi.org/10.3390/environments5010015

FAGARIBA, C.J., SONG, S., \& BAORO, S.K.G.S. (2018). Climate Change Adaptation Strategies and Constraints in Northern Ghana: Evidence of Farmers in Sissala West District. Sustainability. DOI: https://doi.org/10.3390/su10051484

FAMOYE, F., WULU, J.T., \& SINGH, K.P. (2004). On the Generalized Poisson Regression Model with an Application to Accident Data. Journal of Data Science, 2: 287-295.

http://citeseerx.ist.psu.edu/viewdoc/download?doi=10.1. $1.456 .629 \&$ rep $=$ rep $1 \&$ type $=$ pdf

FAO (2016). Leaving no one behind. Addressing climate change for a world free of poverty and hunger. FAO's work on climate change poverty and hunger. http://www.fao.org/3/i6371en/I6371EN.pdf.

GHANA STATISTICAL SERVICE (GSS) (2013). Regional Analytical Report. Northern Region. Ghana Statistical Service. Accra, Ghana. https://s3-us-west2.amazonaws.com/new-ndpc-

static1/CACHES/PUBLICATIONS/2019/01/21/2010_P HC Regional_Analytical_Reports_Greater_Accra_Regio $\underline{\text { n.pdf }}$

GSS. GHANA STATISTICAL SERVICE (2013). 2010 Population and Housing Census. Non-Monetary Poverty in Ghana. Ghana Statistical Service, Accra, Ghana. July 2013. http://www.statsghana.gov.gh/

GREENE, W.H. (2002). Econometric Analysis: fifth edition. New York University. https://spu.fem.uniag.sk/cvicenia/ksov/obtulovic/Mana\% C5\%BE.\%20\%C5\%A1 tatistika\%20a\%20ekonometria/Ec onometricsGREENE.pdf

HALLEGATTE, S., MOOK, B., LAURA, B., MARIANNE, F., TAMARO, K., ULF, N., JULIE, R., DAVID, T., \& ADRIEN, V-S. (2016). Shock Waves: Managing the Impacts of Climate Change on Poverty. Climate Change and Development Series. Washington, DC: World Bank. License: Creative Commons Attribution CC BY 3.0 IGO. DOI: https://doi.org/10.1596/978-1-
4648-0673-5

IPCC (2001). Glossary- Climate Change. Education Centre - Arctic Climatology and Meteorology. NSIDC National Snow and Ice Data Centre. Glossary, in IPCC TAR WG1 2001

LAWSON, E.T., ALARE, R.S., SALIFU, A.R.Z., \& THOMPSON-HALL, M. (2019). Dealing with climate change in semi-arid Ghana: understanding intersectional perceptions and adaptation strategies of women farmers. Geo Journal, 1-14. DOI: https://doi.org/10.1007/s10708019-09974-4

LI, Q., \& TRIVEDI, P. K. (2009). Impact of prescription drug coverage on drug expenditure of the elderly evidence from a two-part model with endogeneity. Mimeo Paper available at: https://pdfs.semanticscholar.org/8f4b/50a49e1ac988c70b a17c15a4daad5c392fdd.pdf

KRANJAC-BERISAVLJEVIC, G., BLENCH, R.M., BAYORBOR, T. B., TURTON, C. N., ABDULAI, A. S., BOYD, C., OBENG, F., \& DRAKE, E. (1999). Rethinking natural resource degradation in semi-arid subSaharan Africa: The case of semi-arid Ghana. London, Overseas Development Institute. http://www.odi.org.uk/rpeg/soil degradation/ghlit.pdf MIRANDA, A. (2004). FIML estimation of an endogenous switching model for count data. The Stata Journal 4 (1), 40-49. https://pdfs.semanticscholar.org/2393/49d86031f2ad744 34a9864d4a32154209d75.pdf

MULLAHY, J. (1997). Instrumental-Variable Estimation of Count Data Models: Applications to Models of Cigarette Smoking Behaviour. Review of Economics and Statistics, $\quad 79, \quad 586-593 . \quad$ DOI: https://doi.org/10.1162/003465397557169

NKEGBE, P., \& SHANKAR, B. (2014). Adoption intensity of soil and water conservation practices by smallholders: evidence from Northern Ghana. Bio-based and Applied Economics, 3(2): 159-174. DOI: https://doi.org/10.13128/BAE-13246

OBENG, F. K, AWASINA R. A. \& AYAMBILA S. N. (2016). Factors Influencing the Adoption of Climate Change Adaptation Strategies by Smallholder Farmers in East Mamprusi District of Northern Region. Ghana. Ghana Journal of Science, Technology and Development, 4 (2), 84-95.

SCHELLHORN, M. (2001). The Effect of Variable Health Insurance Deductibles on the demand for Physician Visits. Health Economics, 10: 441-456. DOI: https://doi.org/10.1002/hec.630

SKOUFIAS, E., RABASSA, M., OLIVIERI, S., \& BRAHMBHATT, M. (2011). The Poverty Impacts of Climate Change. Poverty Reduction and Economic Management Network (Prem). Economic Premise. The World Bank.

TOMPKINS, E. L., and ADGER, W. N. (2003). Building resilience to climate change through adaptive management of natural resources. Tyndall centre for climate change research working paper 27.

TERZA, J. V., KENKEL, D. S., LIN, T.-F., \& SAKATA, S. (2008). Care-giver advice as a preventive measure for drinking during pregnancy: Zeros, categorical outcome responses, and endogeneity. Health Economics, 17, 41- 
54. DOI: https://doi.org/10.1002/hec.1232

TERZA, J. (1998). Estimating count data models with endogenous switching: Sample selection and

endogenous treatment effects. Journal of Econometrics, 84: 129-154. DOI: https://doi.org/10.1016/S03044076(97)00082-1

TEYE, J.K., YARO, J.A., \& BAWAKYILLENUO, S. (2015). Local farmers' experiences and perceptions of climate change in the Northern Savannah zone of Ghana. International Journal of Climate Change Strategies and Management, $\quad 7 \quad$ (3):327-347. DOI: https://doi.org/10.1108/IJCCSM-05-2014-0066
UNFCCC (2007b). Report on the African Regional Workshop on Adaptation. FCCC/SBI/2007/2. UN Office at Geneva, Switzerland.

http://unfccc.int/resource/docs/2007/sbi/eng/02.pdf

VAN OPHEM, H. (2000): Modelling Selectivity in Count Data Models. Journal of Business \& Economic Statistics 18 503-511. DOI: 